\title{
Recontorno cosmético em dentes anteriores com resina composta - revisão de literatura
}

\section{Cosmetic recontour on anterior teeth with composite resin- literature review}

DOI: $10.46919 / \operatorname{archv1n3-002}$

Recebimento dos originais: 10/03/2020

Aceitação para publicação: 10/04/2020

\author{
Rafaela Zeni \\ Graduada em Odontologia pela Universidade Tuiuti do Paraná \\ Instituição: Universidade Tuiuti do Paraná \\ Endereço: Sydnei Antonio Rangel Santos, 238, Bairro Santo Inácio - Curitiba, Paraná, CEP: 82010-330 \\ E-mail: zeni.rafaela@outlook.com \\ Yali Carvalho Ribeiro de Castro \\ Graduada em Odontologia pela Universidade Tuiuti do Paraná \\ Instituição: Universidade Tuiuti do Paraná \\ Endereço: Sydnei Antonio Rangel Santos, 238, Bairro Santo Inácio - Curitiba, Paraná, CEP: 82010-330 \\ E-mail: yalirc@hotmail.com

\begin{abstract}
Albano Luis Bueno
Doutor em Dentistica Restauradora pela PUC-PR

Instituição: Universidade Tuiuti do Paraná

Endereço: Sydnei Antonio Rangel Santos, 238, Bairro Santo Inácio - Curitiba, Paraná, CEP: 82010-330

E-mail: albanoluisbueno@gmail.com

Luciano A. Francio

Mestre em Odontologia pela PUC-MG

Instituição: Universidade Tuiuti do Paraná

Endereço: Sydnei Antonio Rangel Santos, 238, Bairro Santo Inácio - Curitiba, Paraná, CEP: 82010-330

E-mail: luciano.francio@gmail.com
\end{abstract}

\begin{abstract}
RESUMO
INTRODUÇÃO: Agenesia de dentes do grupamento anterossuperior é de fácil percepção por afetar a estética do sorriso, sendo esse o motivo principal da busca por tratamento nesses casos. A avaliação do sorriso deve abranger diversos aspectos desde a composição facial até características morfológicas dos elementos dentários e, dessa forma, se qualquer um desses aspectos forem afetados, o sorriso se torna esteticamente inadequado. Os novos tempos pedem padrões cada vez mais claros de sorrisos, inclusive as indústrias de resinas compostas criam cores mais claras devido a solicitação dos pacientes. Com isso o sorriso tem um valor extraordinário na sociedade, sendo ele um importante meio de comunicação e aceitação do indivíduo. METODOLOGIA: Trata-se de uma revisão de literatura baseada no uso do recontorno cosmético em dentes anteriores com resina composta, para correções de imperfeições estéticas. CONCLUSÃO: Mas quando a estética está comprometida, correções com faceta direta em resina composta, pela técnica de estratificação podem oferecer ao dente uma perfeita restauração, proporcionando beleza natural, estética, cor, anatomia, função e ainda sendo de baixo custo, não necessitando de desgastes de tecidos hígidos.
\end{abstract}


Palavras-chave: Resina Composta, Estética, Estratificação, Facetas.

\begin{abstract}
Agenesis of upper in the anterior teeth is easily observed because it affects the smile esthetics, which is the main reason for seeking treatment in such cases. Smile evaluation should cover several aspects from facial composition to morphological characteristics of dental elements and, therefore, if any of these aspects are affected, the smile becomes aesthetically inadequate. Nowadays the smiles patterns is even clearer patterns of smiles, even the composite resin industries create lighter colors due to patients' requests. Thus, the smile has an extraordinary value in society, being an important means of communication and acceptance of the individual. But when aesthetics is compromised, corrections with a direct facet in composite resin, using the stratification technique can offer the tooth a perfect restoration, providing natural beauty, aesthetics, color, anatomy, function and still being low cost, not requiring wear of healthy tissues.
\end{abstract}

Keywords: Composite resins, Stratification, Esthetics, Veneers.

\title{
1 INTRODUÇÃO
}

O método de confecções de facetas para recobrimento da face vestibular dos dentes, teve seu início no século XX com o Dr. Charles Pincus em 1947, onde fixava-se dentes de acrílico com pó adesivo sem qualquer desgaste na estrutura dental, o que consideravam um provisório. ${ }^{1}$

Buonocore em 1955 desenvolveu uma técnica de condicionamento ácido em esmalte e somente a partir de 1963 Bowen desenvolveu as resinas compostas com Bis-GMA, possibilitando o surgimento de técnicas aos procedimentos estéticos adesivos e consequentemente também em relação as facetas de resina composta. ${ }^{1}$

Somente em 1974, Cooley utiliza a resina composta fotoativada, no recobrimento da face vestibular dos dentes anteriores, suas indicações eram para as seguintes situações clinicas: Modificação da forma ou posição dos dentes; Correção estética de defeitos estruturais; Modificação de cor; Retentores de prótese adesiva; Reabilitação oclusal; e Reparo de próteses. ${ }^{1}$

A beleza tem sido cada vez mais valorizada e com isso almeja-se um sorriso perfeito, tanto para a correção de patologias dentais, quanto para satisfazer as necessidades psicológicas e devido à grande influência nas relações interpessoais ou até mesmo por imposições socioculturais em que o paciente se insere. Portanto, os resultados estéticos vêm para proporcionar o sentimento de bem-estar de modo que a odontologia não trata somente das questões relacionadas à boca, mas também das emoções do indivíduo.

A harmonia do sorriso provem de uma de combinações morfológicas que, combinadas e organizadas, se tornam agradáveis ao olhar e ela provem de uma constante matemática conhecida como proporção áurea. Mas infelizmente tais proporções não são uma característica comum em toda população, pois cada paciente tem suas particularidades e deve-se analisar um todo, para obter-se o resultado mais harmônico e natural possível. 
Para uma correta execução das facetas diretas, deve-se compreender parâmetros de fluorescência, opalescência, translucidez, cor de modo a realizar uma correta aplicação, as diferentes camadas de resina e entre outros parâmetros, estas aplicações de resina em diferentes camadas são denominadas de estratificação.

Portanto o recontorno cosmético e facetas diretas são técnicas não invasivas, que preservam a estrutura dental sadia e suas indicações são para modificação de formato, cor, comprimento, alinhamento dos dentes anteriores e textura de superfície. ${ }^{2}$

As vantagens das facetas diretas são: sessão única; reparo fácil; rápido; controle da cor e dor formato; custo reduzido; preparo conservador; não necessita de provisório. Suas desvantagens: menor resistência mecânica; maior manchamento e contração da resina que pode gerar falha na união adesiva com a estrutura dental. A técnica de facetas em resina composta oferece ao paciente uma opção mais rápida, econômica e que não irá prejudicar a estrutura dentária sadia. ${ }^{2}$

O presente estudo tem por objetivo apresentar uma revisão de literatura, sobre reanatomização dental através das facetas em resina composta na região anterior.

\section{METODOLOGIA}

Trata-se de uma revisão de literatura para conclusão de curso, baseada no uso do recontorno cosmético em dentes anteriores com resina composta, para correção de: fechamento de pequenos diastemas, dentes com superfícies recobertas com restaurações antigas insatisfatórias, situação de urgência estética (fratura), dar volume aos dentes, corrigir lascas, modificação de cor e formato. Foram inclusas neste estudo as publicações dos anos 2006 a 2020. Para construção da revisão de literatura foram utilizadas as seguintes bases de dados: Google acadêmico, Pubmed e Livros. As palavras-chaves utilizadas para pesquisa foram: Resina, Faceta Direta, Estratificação, Recontorno Cosmético e Estética Dental.

\section{DISCUSSÃO}

O sorriso é a porta de entrada no que diz respeito a comunicação e a expressão da emoção, mas a beleza do sorriso não depende apenas do correto posicionamento dentário e esquelético, mas também da anatomia e funcionamento da musculatura labial. ${ }^{3,4}$ Um sorriso agradável é parte importante na composição do aspecto psicológico do indivíduo, onde está diretamente relacionada com a aceitação do indivíduo na sociedade com questões culturais, psicológicas e segurança, portanto é necessário que o dentista perceba o que realmente é importante para aquele paciente, antes mesmo de planejar o caso clínico. $^{3-5}$ Nenhum rosto é completamente simétrico, a maioria das pessoas tem características faciais assimétricas, mas a simetria não leva automaticamente à beleza, portanto fica claro que o próprio 
espectador é um fator relevante para avaliar e sentir a beleza e um fator essencial que contribui significativamente para a atratividade de um rosto é o perfil. ${ }^{3-5}$

A obtenção da estética ideal no entanto, frequentemente tinha como preço a utilização de técnicas complexas, com perda considerável de estruturas dentárias sadias, o fortalecimento dos conceitos de prevenção e conservadorismo, associados diretamente ao desenvolvimento de novas técnicas e matérias estéticos, contribuiu para o aprimoramento das facetas diretas com resina composta. ${ }^{15,16}$ Deparamo-nos com uma população que atribui um valor cada vez mais elevado à estética, com isso a técnica de faceta direta em resina composta está cada vez mais presente, devido a preservação de estrutura dental e uma transformação rápido do sorriso. ${ }^{15,16}$ As restaurações de resina na região anterior tiveram seu início em 1947 com o Dr. Charles Pincus e desde lá representam sempre um desafio para a sua realização, pois deve-se compreender como ligar com: tonalidades, valor e substrato, deve-se levar em consideração também diferentes estabilidades de cor já que a mesma está relacionada com a composição e o grau de conversão $^{1,2,5,8,9}$

Diante de tais anseios, a Odontologia desenvolveu técnicas e materiais que modificam elementos em desarmonia, dando-lhes o aspecto estético requerido pelo paciente e para melhor diagnóstico, para obtenção de um correto planejamento, utiliza-se o método digital para o estudo de caso preliminar (DSD) que permite o planejamento de um sorriso estético final ideal usando apenas fotografias e o computador foi recentemente proposto: um caminho totalmente digital, mas no entanto, está abordagem não substitui o método analógico mais convencional; em vez disso, ele atua como um estágio preliminar que mais precisamente leva à realização, primeiramente, do enceramento e depois do mock-up. ${ }^{6-7}$ Deve-se realizar um protocolo fotográfico e de vídeo, onde são um grande aliado dos dentistas, pois fornecem várias possibilidades de análises dos parâmetros estéticos como: forma da face, tamanho dos terços da face, exposição do lábio em repouso, linha do sorriso, relação da linha média da face com a linha média dental, formato dos dentes e tamanho dos mesmos. ${ }^{3-5,8}$

Impossível pensar em restauração sem adesão, é uma tecnologia que se concentra nas propriedades físicas, mecânicas e químicas, a fim de melhorar a longevidade clínica das restaurações adesivas e tornou-se o padrão-ouro na odontologia estética e restauradora. ${ }^{9,10}$

A técnica de camadas estéticas muitas vezes parece difícil para os profissionais, onde os primeiros esquemas de estratificação propostos eram excessivamente complexos, já hoje existe uma técnica simultaneamente estética, reproduzível e rápida. ${ }^{13}$ Essa técnica é indicada para restaurações de grandes perdas de estrutura dental, ou seja, cavidades classe IV de Black com perda de borda livre. ${ }^{11,15}$ O sucesso das restaurações estéticas diretas no setor anterior é prestígio da dominação do método de estratificação, uma simples técnica e acima de tudo reproduzível. Existem diversas resinas no mercado e, de acordo com os fabricantes os mesmos devem permitir camadas simples e precisas. ${ }^{2}$ Certas noções são necessárias para 
a estratificação, como a cor é definida por três parâmetros: matiz (ou tom cromático), saturação e brilho e além disso é necessário levar em conta: translucidez, fluorescência e opalescência. ${ }^{13,14}$ É importante que conheça bem as características dos substratos, para usar os compósitos compatíveis, além de conhecer as características ópticas de todas as partes do dente restaurado, para obter o resultado mais estético e funcional. $^{2,9,12}$ Este conceito busca resultados mais estéticos, que incluem um conjunto de dentina e esmalte, de acordo com a escala Vita, onde a dentina é mais opaca próximo ou maior que a dentina natura, enquanto o esmalte é intermediário e além dessas camadas também é aplicada uma camada translúcida para simular o bordo incisal. ${ }^{11,14}$ Ao empregar a técnica de estratificação para reproduzir a tonalidade, formato e a translucidez dos dentes, de modo a recuperar a aparência original, reproduzindo assim a estética natural dos dentes, sem a necessidade de uma preparação dentária. ${ }^{12-14}$ Para reproduzir o dente de uma forma natural, é necessário utilizar uma técnica de estratificação anatômica de três camadas, com o compósito que imite a anatomia do dente e dessa maneira se alcança uma relação com a luz semelhante à que acontece quando a luz passa pela estrutura dental natural. ${ }^{12-14} \mathrm{~A}$ resina de dentina não é suficiente para imitar completamente a dentina, portanto em restaurações volumosas, Vanini descreve o uso de três resinas de dentina diferentes aplicadas em camadas oblíquas e é importante ressaltar que elas favorecem a estética. ${ }^{11,14}$ A técnica de Vanini usando três camadas, usa-se uma camada adicional de resina entre a dentina e esmalte, o objetivo dessa camada é imitar a camada de esmalte amorfo, portanto em restaurações volumosas, Vanini descreve o uso de três camadas diferentes aplicadas em camadas oblíquas e é importante ressaltar que aplicações assim favorecem a estética, melhorando as forças de contração dentro do compósito. ${ }^{11,13,14}$ Apesar do aprimoramento das resinas, a técnica de estratificação de duas camadas não permite restaurações satisfatórias, como nos casos de restaurações de ângulos ou bordas incisais. Nesses casos, deve-se optar pela técnica de Vanini, o qual a estratificação é de três camada. $^{13,14}$

\section{CONCLUSÃO OU CONSIDERAÇÕES FINAIS}

O recontorno cosmético em dentes anteriores são excelentes opções de tratamento graças à preservação da estrutura dental, uma vez que não há necessidade de confecção de bisel para mascarar a interface dente/resina, técnica rápida e simples.

O planejamento é fundamental para a obtenção do sucesso na reabilitação oral e a técnica de estratificação das diferentes camadas de resina implica num resultado estético satisfatório não apenas em cor, mas principalmente na reprodução das propriedades óticas dos dentes naturais.

Mesmo o recontorno cosmético através das facetas em resina composta, si bem planejadas podem evitar o desgaste desnecessários de estruturas sadias, favorecendo a longevidade clinica destes casos. 


\section{REFERÊNCIAS}

1. Nishimori, LE, Beloti, AM. Resistência mecânica de facetas cerâmicas com e sem preparo de overlap. PIBIC/Cesumar. 2016; 8(1):85-90.

2. Ferracane, JL. Resin Composite--State of the Art. Dent Mater. 2011;27(1):29-38.

3. Borelli, C, Berneburg, M. "Beauty Lies in the Eye of the Beholder"? Aspects of Beauty and Attractiveness. J Dtsch Dermatol Ges. 2010; 8(5):326-30.

4. Al-Habahbeh, R, Al-Shammout, R, Al-Jabrah, O, Al-Omari, F. The Effect of Gender on Tooth and Gingival Display in the Anterior Region at Rest and During Smiling. Eur J Esthet Dent. 2009; 4(4):382-95.

5. KönigI, K. The four temperaments. Arte Méd Ampl. 2013; 33(1): 5-7.

6. Pastor, FP, Coachman, C, Calamita, M. Planejamento Digital Estético: Protocolo Digital Smile Design (DSD). In: Albernaz Neto, A, Barbosa, LC, Barreto, MA, Moreira, AA. Estética do Sorriso em Reabilitação Protética. São Paulo: Napoleão; 2014.

7. Zirmmermann, M, Mehl, A. Virtual smile design systems: a current review. Int. J. Comput. Dent. 2015; 18(4)303-317

8. Brandão, RCB, Brandão, LBC. Procedimentos para finalização em Ortodontia:dimensões e proporções dentárias (micro-estética). Dental Press J Orthod. 2013; 18(5):147-74.

9. Fonseca, M. The Aesthetics Yearbook. Nova Odessa, SP: Napoleão; 2020.

10. Papadogiannis, D, Dimitriadi, M, Zafiropoulou, M, Gaintantzopoulou, MD, Eliades, G. Universal Adhesives: Setting Characteristics and Reactivity With Dentin. Materials (Basel). 2019; 12(10):1720.

11. Vanini, L. Conservative Composite Restorations that Mimic Nature: A Step-by-Step Anatomical Stratification Technique. Journal of Cosmetic Dentistry. 2010; 26(3): 80-101.

12. Villarroel, M, Fahl, N, Sousa, AM, Oliveira Jr, OB. Direct Esthetic Restorations Based on Translucency and Opacity of Composite Resins. J Esthet Restor Dent. 2011;23(2):73-87

13. Decerle, N, Turpin, YL, Desa, C, Hennequin, M. Le point sur la stratification esthétique des composites. AOS. 2011; 256: 341-352.

14. Correia, A, Oliveira, MA, Silva, MJ. Conceito de Estratificação nas Restaurações de Dentes Anteriores com Resina Compostas. Rev. port. estomatol. cir. maxilofac. 2006; 43(6): 171-178.

15. Ribeiro, LFA, Grajeda, FMC. Cor na odontologia restauradora moderna:revisão de literatura. UniCor. 2019; 9(1): 57-68.

16. Yanikian, CRF, Yanikian, F, Sundfeld, D, Lins, RBE, Martins, LRM. Direct Composite Resin Veneers in Nonvital Teeth: A Still Viable Alternative to Mask Dark Substrates. Oper Dent. 2019; 44(4):159-166. 